\title{
Damage at a distance
}

SIR-The Loma Prieta earthquake registered 7.1 on the Richter scale. It occurred at 17:04 hours on 17 October 1989, along the San Andreas fault in the Santa Cruz mountains. Surprisingly, it destroyed about 40 houses in the Marina district of San Francisco, 67 miles away from the epicentre. Here, I would like to suggest an explanation for this damage.

In the 5 minutes after the main shock, many residents of the Marina district observed a mixture of sand, water and mud surfacing in their garages or backyards. In one apartment building 1 metre of sand oozed through the concrete floor. Many people reported that the mixture of water and sand emanated from the cracks and from the drainage openings of their garage floors. The sand ejecta, also called sand boils, sand spouts, water spouts, craterlets or sand volcanoes, were caused by the phenomenon of liquefaction, a physical process that transforms a solid mass of wet sands into a liquid mixture of sand and water!.

Figure 1 represents the $900 \times 600$ metre area of the Marina district which my students and I investigated. Located between the Presido military reservation and Fort Mason, the area extends from Fillmore to Baker Streets from east to west, and from Marina Boulevard to Chestnut Street from north to south. We recorded a total of 74 sand boils in this area, the largest of which had a volume in excess of 3.5 cubic metres (Fig. 2). The ejecta were made of a grey and odourless mixture of fine dune sand and San Francisco bay mud.

The sand boils covered only the northeast corner of the Marina district (Fig. 1), a distribution related to the construction history of the district. By 1894, a sea wall and a lagoon had been constructed along the original 1892 shoreline of the district. During the 1906 earthquake, Lawson reported ${ }^{2}$ a severe ground shaking near this lagoon. By 1915, the lagoon had been filled to host the Panama-Pacific international exposition, after which some buildings were erected on the debris left over while others were directly built on man-made land. The Marina district was therefore constructed on a liquefiable landfill predisposed to ground motion amplification.

All our 74 observations on sand boils fall within the perimeter of the 1906 lagoon. The soils filling the lagoon were saturated by the high tide during the Loma Prieta earthquake. They liquefied, spread laterally and moved relative to the edge of the lagoon. As shown in Fig. 1, three apartment buildings collapsed and a serious fire was ignited along the shoreline of the old lagoon.

\section{Department of Civil Engineering,}

J. P. BARDET

\section{University of California,}

Los Angeles,

California 90089-0242, USA

1. National Research Council Liquefaction of Soils during Earthquakes 18-20: 72-73 (National Academy Press 1985).

2. Lawson, A.C. et al. Rep. State Earthquake Invest. Comm. 404-405 (Carnegie Institution, Washington. DC. 1908)

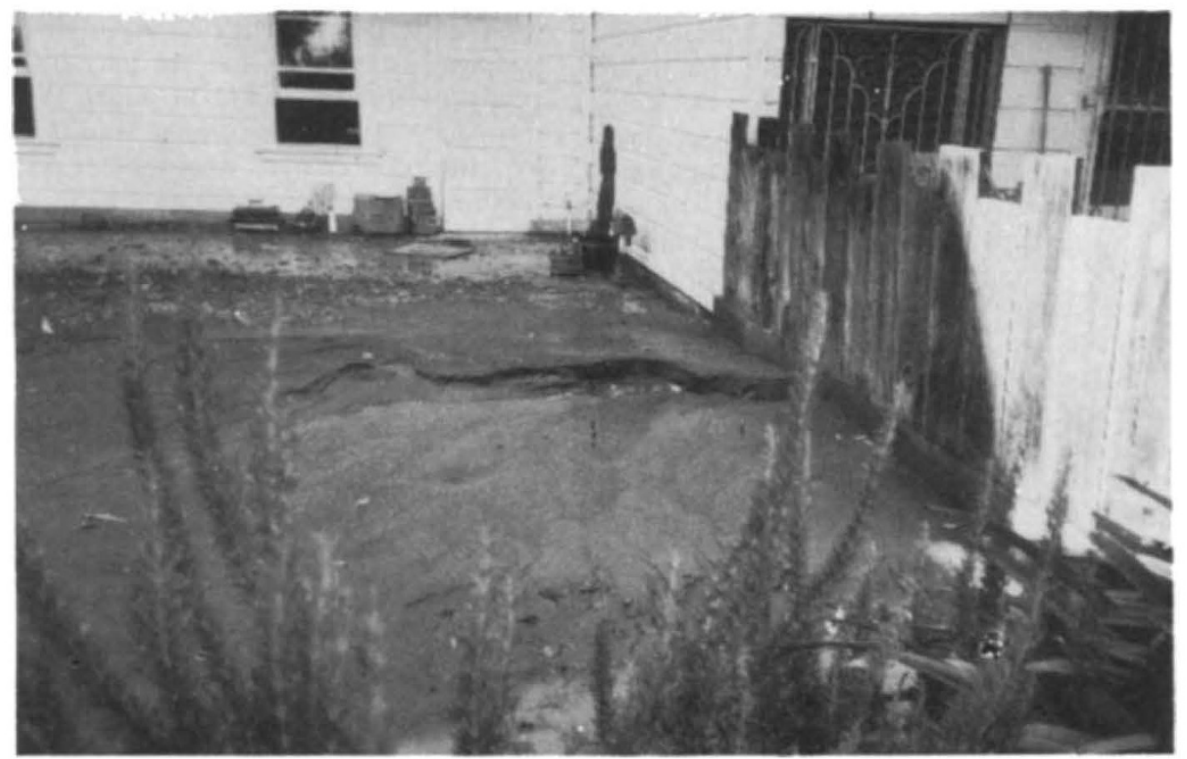

FIG. 2 A large sand boil (3.5 cubic metres) with two craters emerged in a backyard a few minutes after the main shock. The mixture of water, sand and clay flowed through the wooden fence and

completely covered the neighbouring backyard.

\section{Expanding zeolite- type nets}

SIR-Zeolite materials have structures based on a framework of cornerconnected tetrahedra with primarily silicon, aluminium or phosphorus at their centres and two-coordinated oxygen atoms at the corners. More than 60 topologically distinct frameworks of this type have been found so far in minerals and synthetic phases. Frameworks of this kind belong to the family of $(4 ; 2)$-connected three-dimensional nets, of which an infinite number can be conceived ${ }^{\prime}$. I would like to draw attention to a berylliumcontaining structural unit, which could in theory be used to 'expand' any zeolitetype net, resulting in a structure of low density and large pore size.

Zeolites possess pores of well defined dimensions that are of importance in cata. lysis and in separation processes. Among the aluminosilicates, the largest known apertures consist of 12 tetrahedra; lowdensity nets with larger rings would have great potential for industrial applications. Theoretical structure-building mechanisms that allow the expansion of a few specific nets have been presented ${ }^{2-4}$ and one of these expanded nets, with 18 membered rings, has now been found ${ }^{3}$ in the aluminophosphate VPI-5.

The isolated $\left[\mathrm{Be}_{+} \mathrm{Si}_{+} \mathrm{O}_{1]}\right]^{10-}$ ion ${ }^{n}$ exists in the compound $\mathrm{Na}_{11} \mathrm{Be}_{4} \mathrm{Si}_{4} \mathrm{O}_{17}$ (inset in the figure). In the centre of the ion, four $\mathrm{BeO}_{+}$tetrahedra share an oxygen atom. The other three oxygen atoms of each $\mathrm{BeO}_{+}$group are two-coordinated through corner-sharing between $\mathrm{BeO}_{4}$ and $\mathrm{SiO}_{4}$ tetrahedra. Three of the corners of $\mathrm{a} \mathrm{SiO}_{4}$ tetrahedron are shared with $\mathrm{BeO}_{4}$ tetra- 